\title{
Randomization Weight
}

National Cancer Institute

\section{Source}

National Cancer Institute. Randomization Weight. NCI Thesaurus. Code C93642.

The relative proportion of subjects to be randomized. 